\title{
DiREITOS HUMANOS E JUSTIÇA: A PERSPECTIVA DE GRADUANDOS EM CURSOS DE LICENCIATURA E BACHARELADO
}

\author{
Human Rights and justice: the perspective of undergraduates in \\ licentiate's and bachelor's degree programs
}

\section{Derechos humanos y justicia: la perspectiva estudiantil desde los cursos de licenciatura y bachilleratoen Brasil}

RESUMo O presente relato de pesquisa tem por objetivo revelar a percepção de estudantes de educação superior sobre direitos humanos e justiça.Participaram da pesquisa 85 estudantes dos primeiros e últimos anos de nove cursos: quatro de bacharelado e cinco de licenciatura de uma instituição do interior do Estado de São Paulo. A análise qualitativa dos dados foi feita mediante a luz de documentos que protegem os direitos constitucionais de todas as pessoas o que implica, necessariamente, uma aprendizagem integral promotora do desenvolvimento humano. Os resultados mostram que os alunos ainda não relacionam direitos humanos e justiça a temas como aprendizagem de convívio, diversidade, cidadania, corrupção, raça e etnia, gênero, classe social, escolha religiosa, orientação sexual, opção política, ou qualquer diferença. É preciso incorporar ao processo educativo que "Direito" é exercício e prática humana política, fundamental para a consciência da cidadania, portanto é urgente que a universidade promova de forma obstinada a educação em Direitos Humanos na formação do aluno, o que irá contribuir para a propagação do compromisso social e para uma cultura de paz.

PALAVRAS-CHAVE: EDUCAÇÃO SUPERIOR E DIREITOS HUMANOS; UNIVERSIDADE E CIDADANIA; EdUCAÇÃO E DiREITOS HUMANOS

ABSTRACT The present research report is aimed to reveal the perception of higher education students about human rights and justice. 85 students from first and last years of nine graduation courses took part in the research: four from bachelor's degree programs and five from licentiate's degree programs of an institution located in the interior of the State of São Paulo. The qualitative analysis of the data was made through the documents that protect the Constitutional Rights of all people, which implies necessarily a full-time learning process that promotes human development. The results show that the students still don't relate human rights and justice to topics like learning about conviviality, diversity, citizenship, corruption, race and ethnicity, gender, so-
Sonia Maria Ferreira Koehler Centro Universitário Salesiano de São Paulo UNISAL- U.E. Lorena

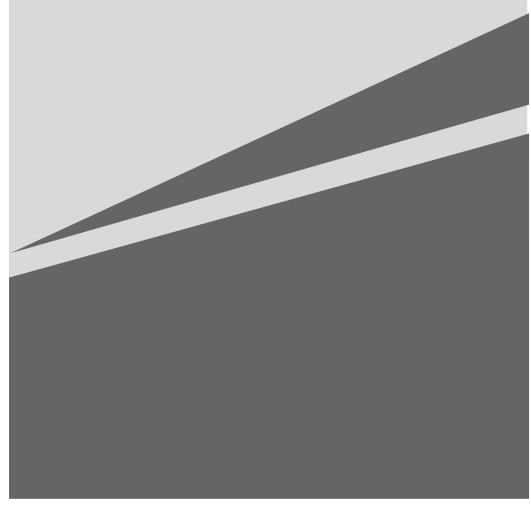


cial class, religious choice, sexual orientation, political choice or any other differentiation. It's necessary to incorporate to the educational process the notion that "Right" is exercise and human political practice, fundamental to the consciousness of citizenship; therefore it is urgent that the university promotes obstinately the education in Human Rights in the student's formation, which will contribute to the propagation of the social commitment and to a culture of peace.

KEYWORDS: HIGHER EDUCATION AND HUMAN RIGHTS; UNIVERSITY AND CITIZENSHIP; EDUCATION AND HUMAN RIGHTS.

RESUMEN Este informe tiene como finalidad revelar lapercepción de losestudiantes de laeducación superior sobre losderechos humanos y justicia. Han participado de lainvestigación 85 estudiantes de losprimeros y últimos años de nueve cursos: cuatro de licenciatura y cinco de maestría, de una instituciónenel interior del Estado de São Paulo. El análisiscualitativo de datos se realizó por laluminiscencia de documentos de protección a losderechosconstitucionales de todas las personas, lo que resulta, esencialmente, enunaprendizaje integral que promueveeldesarrollo humano. Lasconclusionesmuestran que losestudiantestodavía no relacionanderechos humanos y justicia a temáticas como elaprendizajedelconvivio, ladiversidad, laciudadanía, corrupción, raza y etnia, género, clasessociales, opción religiosa, orientación sexual, opción política, o cualquierotra diferencia. Así, es necesario agregar al proceso educativo laidea de que el "Derecho" es unejercicio y una práctica humana política fundamental para laconciencia de laciudadanía, por lo tanto, es urgente que launiversidadpromueva de manera tenaz laeducación de Derechos Humanos enlainstruccióndelestudiante, contribuyendo para lapropagacióndelcompromiso social y para la cultura de la paz.

PALABRAS-CLAVE: EDUCACIÓN SUPERIOR Y DERECHOS HUMANOS; UNIVERSIDAD Y CIUDADANÍA; EDUCACIÓN Y DERECHOS HUMANOS.

\section{INTRODUÇ̃̃o}

$\mathrm{E}$ ste estudo é produto de uma pesquisa desenvolvida pelo grupo de pesquisas do Observatório de Violências nas Escolas do Centro Universitário Salesiano de São Paulo (UNISAL). O Observatório, sediado no UNISAL, campus São Joaquim, em Lorena/SP, desde 2008 mantém parceria com a Cátedra UNESCO de Juventude Educação e Sociedade da Universidade Católica de Bra- sília (UCB), constituindo uma rede internacional e nacional de pesquisa, ensino e extensão.

A pesquisa apresentada neste artigo"Direitos humanos e justiça: a perspectiva de graduandos em cursos de licenciatura e bacharelado"se desenvolveuvinculada ao projeto de investigação em rede denominadoPercepções de Justiça e Direitos Humanos de Grupos Sociais Específicos no período 20132016, articulada pela Cátedra UNESCO de Ju- 
ventude Educação e Sociedade ${ }^{1}$ ese norteia pela necessidade de revelar as percepções e a sensibilidade dos estudantes de educação superior aos direitos humanos e aos conceitos de justiça. Também procura refletir sobre a dificuldade de se viver em um mundo pós-moderno guiado pelas exigências do mercado e que relega os direitos humanos.

\section{Direitos humanos E EDUCaÇÃo}

\author{
Pra Não Dizer Que \\ Não Falei de Flores \\ Geraldo Vandré (1968) \\ Caminhando e cantando \\ e seguindo a canção \\ Somos todos iguais \\ braços dados ou não \\ Nas escolas, nas ruas, \\ campos, construções \\ Caminhando e cantando \\ e seguindo a canção \\ Vem, vamos embora, \\ que esperar não é saber \\ Quem sabe faz a hora, \\ não espera acontecer
}

A partir da afirmação, "os direitos do homem são direitos históricos, que emergem gradualmente das lutas que o homem trava por sua própria emancipação e das transformações das condições de vida que essas lutas produzem" (BOBBIO,1992, p. 31), somos seres sociais, portanto a transformação e a efetiva-

\footnotetext{
Parte deste estudo foi publicado nos Anais completos do XII EDUCERE 2015, KOEHLER, S.M. F.; SANTOS, D. T. Convivência escolar: representações de alunos de ensino superior. Congresso de Educação da PUC/PR. 26 a 29 de outubro de 2015.0 estudo teve a participação de Daniéverson Tadeu Dantas dos Santos. Licenciado em Psicologia, acadêmico de Iniciação Científica e bolsista CNPq no período 2014/2015/2016, que auxiliou na aplicação do instrumento de pesquisa e no tratamento dos dados para a análise.Outro recorte foi feito e publicado como capítulo no livro"Juventude Universitária: Percepções sobre Justiça e Direitos Humanos”, CALIMAN, G. editado pela Liber Livro em 2016.
}

ção dos direitos humanos devem passarpelo processo educacional formal e informal. A educação exerce um papel fundamental para a promoção de direitos humanos;por intermédio dela, se imagina ser possível, desde cedo, a germinação de um pensamento de caráter universalista, voltado ao respeito e tolerância às diferenças. O Plano de Ação do Programa Mundial para Educação em Direitos Humanos (2006) assim define:

Em conformidade com os citados instrumentos, que estabelecem as bases para uma definição da educação em direitos humanos segundo o acordado pela comunidade internacional, a educação em direitos humanos pode ser definida como o conjunto de atividades de capacitação e difusão de informação, orientadas para criar uma cultura universal na esfera dos direitos humanos mediante a transmissão de conhecimentos, o ensino de técnicas e a formação de atitudes, com a finalidade de: fortalecer o respeito aos direitos humanos e às liberdades fundamentais; desenvolver plenamente a personalidade humana e o sentido da dignidade do ser humano; promover a compreensão, a tolerância, a igualdade entre os sexos e a amizade entre todas as nações, os povos indígenas e os grupos raciais, nacionais, étnicos, religiosos e linguísticos; facilitar a participação efetiva de todas as pessoas numa sociedade livre e democrática na qual impere o Estado de direito; fomentar e manter a paz; promover um desenvolvimento sustentável centrado nas pessoas e na justiça social. (UNESCO, 2006, p. 15).

No Brasil, o Plano Nacional de Educação em Direitos Humanos (PNEDH)de 2007bevidencia que a promoção e exercício de cidadania requerem uma educação inspirada em 
valores humanistas, formando cidadãos conscientes de seus direitos e deveres, reconhecedores da dignidade humana e compromissados com a solidariedade internacional.

A realidade, infelizmente, ainda vai na contramão e as escolas brasileiras ainda são espaços de violências, exclusões e incivilidades.

Percebe-se que a dificuldade de convivência não acontece somente nas relações entre os alunos, mas também nas relações entre alunos e professores, alunos e gestores, gestores e professores. Estevão (2008,p.5) demonstra que muitasdas escolas acabam se tornando uma "arena política" onde metas, interesses, objetivos e jogos de poder se realizam. Nessas escolas, há uma questão de poderes e autoridades que propiciam diversas respostas polarizadas entre o acatamento e resistência ativa. Essa escola é permeada por uma perversidade advinda do:

(...) imobilismo que a escola por vezes propicia; da mudança que favorece os já favorecidos, que aumenta o poder de quem já é poderoso; do autoritarismo e controle, que diminuem os direitos dos alunos; da falta de transparência e impunidade; da discriminação e dos privilégios dos "herdeiros"; da impermeabilidade à crítica; da rotina dos discursos, atitudes e práticas; da discrepância entre os discursos e a ação; da sensualidade do poder que obriga a uma atitude submissa; da atenção dispensada apenas aos alunos mais brilhantes; do processo de avaliação como processo hierarquizador, de rotulagem dos alunos; da domesticação e formação bancária; da ocorrência de trabalho inútil e sem esperança (ESTEVÃO, 2008, p.6).

Del Prette (2001,p.35) demonstra que o desenvolvimento humano é um processo dinâmico, não-linear, de "construção, reconstrução e plasticidade" entre características do indivíduo e do ambiente. Esse aspecto também é enfatizado por Piaget (1994), quando demonstra que o desenvolvimento humano acontece por estágios e trocas constantes entre indivíduos e meio como resultado das interações sociais e, por sua vez se configura no cerne do desenvolvimento moral "os valores não são internalizados pelo sujeito passivamente, mas é a partir de trocas e conflitos com o meio que ele vai construindo seus valores morais" (MOLINARI, 2012, p. 153). Portanto, o senso de moralidade é construído e internalizado pelo sujeito, a partir da sua experiência, sobre o significado e o agir bem ou agir mal, sobre comportamentos adequados ou inadequados, muito além das leis e resoluções estabelecidas pelo Estado.

Um dos maiores entraves à educação em Direitos Humanos é quebrar o paradigma de que a escola é somente formadora de competências técnicas, esquecendo-se do caráter socializante que a educação possui.

Segundo uma pesquisa realizada pelo Observatório de Violências nas Escolas da PUC/ $\mathrm{PR}$, intitulada "Educação básica de qualidade para todos: políticas e práticas nos contextos das escolas públicas", observa-se que ao serem perguntados sobre qual a finalidade da educação escolar, 64\% dos professores, 50\% dos gestores e $80,15 \%$ dos pais de alunos emitiram respostas que se alinharam a uma visão conservadora sobre o tema (EYNG, 2013, p.48). $A$ visão conservadora é exemplificada a partir dos seguintes posicionamentos: "Dar ao aluno um futuro, uma profissão"; "Transmitir conhecimento formal e técnico". Nota-se o caráter hegemônico, que não permite a diversidade, além de não promover o exercício do pensar.

Os interesses da ideologia vigente se apresenta como um dos grandes entraves à promoção de ideais igualitários no século XXI;por meio dessa forma de educação, a universidade, que no passado tinha a missão de formar cidadãos socialmente ativos e pensantes, hoje é chamada a formar "mão de obra" ativa para o mercado e os alunos procuram o diploma em detrimento do conhecimento e valores. 
Sabe-se que não é simples educar para os direitos humanos em uma sociedade regida pelo consumo, onde a própria educação se tornou uma mercadoria, sendo o acesso gratuito e irrestrito a esta uma das propostas dos direitos humanos. Delors e colaboradores (1998) apontam que a educação não deve restringir-se apenas à formação de pessoas qualificadas aos anseios econômicos, masse expandirao desenvolvimento de talentos e aptidões que cada um possui, ao mesmo tempo em que a missão fundamentalmente humanista da educação é a exigência de equidade que deve orientar qualquer política educativa e as verdadeiras necessidades de um desenvolvimento respeitador do meio ambiente humano e natural, e da diversidade de tradições e de culturas.

Caliman(2013, p. 11) evidencia o desafio dessa temática por intermédio de muitas expressões e demonstra "as manifestações de violência como sintomas de um mal-estar que subsiste a sociedade": drogas, condicionantes culturais e estruturais como a desigualdade social, a negação dos direitos fundamentais, a exclusão social e reitera que "a educação está na base da construção do bem-estar social, da construção de culturas de paz capazes de garantir os direitos humanos e a prevenção da situação de risco" (CALIMAN, 2013, p.13).

Como também propõe o documento sobre a Base Nacional Comum Curricular (BNCC), o mais novo instrumento norteador da Educação Básica, é compromisso da escola:

...propiciaruma formação integral, balizada pelos direitos humanos e princípiosdemocráticos, é preciso considerar a necessidade de desnaturalizarqualquer forma de violência nas sociedades contemporâneas,incluindo a violência simbólica de grupos sociais que impõemnormas, valores e conhecimentos tidos como universais e que nãoestabelecem diálogo entre as diferentes culturas presentes na comunidadee na escola(BNCC, 2017, p. 59).
Ao nosso entender, as questões de Direitos Humanos dizem respeito à totalidade de cada pessoa, corpo, intelecto e psicológico, assim como, todas as dimensões da vida a sua parte intelectual, emocional, social, física, artística, criativa e as suas potencialidades espirituais,desde o nascimento até a morte, o que implica,necessariamente uma aprendizagem integral, que promova o desenvolvimento da pessoa como um todo. $\mathrm{E}$, se a aprendizagem se faz e se constrói num dado contexto social, engloba todas as experiências quotidianas; portanto é interdisciplinar e transversal aos temas tradicionais nos currículos escolares de todas as fases da vida, do ensino básico (infantil, fundamental e médio) até o ensino superior: graduação, lato sensu ou stricto sensu. Além disso, devemos considerar a ideia da formação permanente comoperspectiva essencial dos nossos dias, para além de uma simples adaptação ao emprego, na concepção mais ampla de uma educação ao longo de toda a vida, concebida como condição de desenvolvimento harmonioso e contínuo da pessoa.

Diante do panorama exposto,torna-se fundamental investigar o conhecimento que os estudantes universitários possuem acerca do significado de direitos humanos e justiça e propor alternativas para a universidade agir. Assim, a investigação se orientou pelo pressuposto da qualidade social da educação, estabelecida como princípio e direito humano fundamental nas políticas sociais, via: Declaração Universal dos Direitos Humanos (ONU, 1948); Constituição da República Federativa do Brasil de 1988(BRASIL, 1988); Lei ${ }^{\circ}$ 8.069, de 13 de julho de 1990, que estabelece o Estatuto da Criança e do Adolescente (BRASIL, 2014); Lei de Diretrizes e Bases (LDBEN) $n^{\circ}$ 9.394-96 (BRASIL, 1996); Plano Nacional de Educação em Direitos Humanos - PNEDH-BRASIL, 2007b;BRASIL, 2007aDecreto $n^{\circ}$ 6.094, de 24 de abril de 2007, que estabelece o Plano de Metas: Compromisso Todos pela Educação;Direitos humanos: percepções da opinião pública: análises de pesquisa nacional, 2010a; Resolução 04/2010, que estabelece as 
Diretrizes Curriculares Nacionais Gerais para a Educação Básica, BRASIL, 2010b; Resolução $n^{\circ}$ 1, de 30 de maio de 2012, que Estabelece Diretrizes Nacionais para a Educação em Direitos Humanos (BRASIL, 2012). Direitos humanos: percepções da opinião pública: análises de pesquisa nacional, 2010 .

\section{A Metodologia da Pesquisa}

\author{
Pra Não Dizer Que \\ Não Falei de Flores \\ Geraldo Vandré (1968) \\ Pelos campos há fome \\ em grandes plantações \\ Pelas ruas marchando \\ indecisos cordões \\ Ainda fazem da flor seu \\ mais forte refrão \\ E acreditam nas flores \\ vencendo o canhão \\ Vem, vamos embora, \\ que esperar não é saber \\ Quem sabe faz a hora, \\ não espera acontecer
}

Participaram da pesquisa estudantes de primeiro e último ano do Centro Universitário Salesiano do campus São Joaquim /Lorena/SP. Foi feito o sorteio de uma turma de cada período: matutino e noturno, abrangendonove cursos: cinco de formação de professoresPedagogia, Psicologia (Licenciatura), Matemática, Filosofia, Históriae quatro cursos de bachareladoPsicologia (Formação de psicólogo), Administração, Ciências da Computação, Direito.

$\mathrm{O}$ instrumento de pesquisa ${ }^{2}$ foi aplicado em 17 turmas. Foram convidados cinco alunos por turma, que se apresentaramde forma voluntária, totalizando 85 participantes: 45 alunos dos cursos de licenciaturas e quarenta alunos dos cursos de bacharelado.

Dado o caráter multicêntrico da pesquisa, foi utilizado o mesmo questionário validado e aplicado pelo grupo de pesquisas do Programa de Pós-Graduação em Educação da Pontifícia Universidade Católica do Paraná PPGE/PUCPR), em 2013.
Consta do questionário a identificação dos participantes: curso, ano, turno, idade, sexo, core religião e, se cursou o ensino médio em escola pública ou particular.

As questões do instrumento, elaborado apenas com questões abertas,objetivou conhecer a percepção dos participantes sobre quatro temas:

I. "Percepções sobre Direitos": "O que você entende por Direitos Humanos?" e "O que você entende por Direitos Humanos na escola?"

II. "Percepções sobre Justiça": "O que você entende por Justiça?" e "O que você entende por Justiça na escola?".

III. "Percepções sobre Convivência escolar": "O que você entende por convivência?" e "O que você entende por convivência na escola?",

IV. "Percepções sobre o curso". Nesta parte, o instrumento abordou algumas questões pertinentes ao Projeto Pedagógico do Curso:"No seu curso são tratadas questões sobre direitos humanos?", "No seu curso são tratadas questões relativas à justiça?" e "No seu curso são tratadas questões que se referem à convivência escolar?3

Para a aplicação dos questionários foi pedida autorizaçãopara a coordenação de cada curso e os professores das salas sorteadas foram informados sobre os procedimentos da aplicação. Na data agendada, os alunos foram abordados coletivamente e informados sobre o objetivo da pesquisa esobre o Termo de Consentimento Livre e Esclarecido (TCLE). Em cada sala, após a explanação, o aplicador solicitava voluntários até a quantidade desejada de cinco participantes que, conduzidos a uma sala de aula, preenchiam o questionário individualmente, mediante assinatura do TCLE.

\footnotetext{
Neste artigo abordaremos as questões temáticas I, II e IV do questionário. A questão III que trata sobre Convivência Escolar consta nos Anais completos do XII EDUCERE 2015, KOEHLER, S.M. F.; SANTOS, D. T. Convivência escolar: representações de alunos de ensino superior. Congresso de Educação da PUC/PR 26 a 29 de outubro de 2015.
} 
Para a análise dos dados do instrumento foi utilizado o software Alceste ${ }^{4}$ (ALCESTE, 2010), que possui a finalidade de analisar dados textuais e desvendar as informações relevantes de um corpus, que pode ser um conjunto de respostas para a mesma pergunta, como no caso desta pesquisa.

Para maior fidedignidade quanto aos resultados obtidos, duas análises foram realizadas para cada pergunta.Após o tratamento das respostas no software Excel, foram submetidas ao Alceste como um corpus, subdividido em 85 Unidades de Contexto Inicial (U.C.I.), cada uma correspondendo a um participantes.

As classes obtidas pelo Alceste são interpretadas sob três perspectivas: a) conteúdo, b) atividade e c) representação.

a) conteúdo, observando-se a lista de palavras ou de unidades de contexto elementar (U.C.E.) que lhes são específicas;

b) atividade, observando-se as passagens de uma classe a outra no decorrer do processo discursivo; e

c) representação, observando-se que as classes formam um sistema e refletem certa estabilização da atividade do sujeito enunciador (REINERT, 2001, p. 34apud LIMA 2008, p. 90).

4 (AnalyseLexicale par Context d'un Ensemble de Segments de Texte), desenvolvido na França em 1990 por Max Reinert. É reconhecida a complexidade do ALCESTE, versátil e transparente na medida em que familiariza os seus processos estatísticos e os resultados apresentados em listas de palavras, configuração das classes, figuras e gráficos resultantes da Análise Hierárquica Descendente e da Análise Fatorial de Correspondência.

5 Na etapa A de análise, o programa reconhece as U.C.I(s) e segmenta o texto, dando origem às Unidades de Contexto Elementar (U.C.E.), que correspondem aos enunciados e são a menor unidade estatística disponibilizada pelo programa, que também reduziu as palavras a suas raízes e calculou a frequência das mesmas. Na etapa B, as U.C.E(s) são classificadas de acordo com o vocabulário dos respondentes e seu conjunto é dividido em formas reduzidas. U.C.E.(s) e formas reduzidas são cruzadas e o método de classificação hierárquica descendente é aplicado, dando origem às classes.
Na etapa C, o programa fornece os dendogramas ${ }^{6}$.Os dados foram trabalhados pela análise de conteúdo que, segundo Bardin (2000, p. 22), se define como "um conjunto de técnicas de análise das comunicações visando obter, por procedimentos, sistemáticos e objetivos de descrição do conteúdo das mensagens, indicadores (quantitativos ou não) que permitam a inferência de conhecimentos".

\section{Perfil dos JOVENS UNIVERSitáRios PARTICIPANTES E APRESENTAÇÃO DOS DADOS}

Pra Não Dizer Que Não Falei de Flores Geraldo Vandré (1968)

Há soldados armados, amados ou não

Quase todos perdidos de armas na mão Nos quartéis lhes ensinam uma antiga lição De morrer pela pátria e viver sem razão

Vem, vamos embora, que esperar não é saber Quem sabe faz a hora, não espera acontecer

Entre os 85 sujeitos, $50,58 \%$ são do sexo feminino e $49,41 \%$, do masculino, $88,23 \%$ dos participantes, se encontravam abaixo dos 30 anos de idade, concentrando-se entre o intervalo de 21 e 22 anos,67,06\% são originários do ensino público. Os alunos do ensino particular perfizeram $28,24 \%$ da amostra.

No tópico "raça e etnia", $64,71 \%$ dos alunos se consideram brancos ou caucasianos, $17,65 \%$ pardos ou mulatos, 10,59\% preferiram não responder e 7,06\% informaram ser negros ou pretos. No quesito "religião", $64,71 \%$ decla-

6 Dendograma: representação gráfica resultante de uma análise estatística.Cf. arquivos no Observatório de Violências do UNISAL/Lorena/SP. Contato:obsviolencia@lo.unisal.br 
raram-se católicos, 12,94\% deixaram a questão em branco, 9,41\% se consideraram ateus ou disseram não pertencer a qualquer religião, $5,88 \%$ se consideram evangélicos de qualquer denominação e 3,53\% espíritas. Quanto à grande quantidade de católicos, deve-se lembrar que a instituição onde a pesquisa foi realizada é confessional católica.

$\mathrm{Na}$ análise das respostas referente à questão "O que você entende por Direitos humanos na escola", osoftwareforneceu três classes:

Classe1,Denominada "Respeito dentro da escola", obteve-se $28 \%$ das Unidades de Contexto Elementar (U.C.E.), essa classe constitui-se em discursos sobre a igualdade entre os alunos e o respeito que estes devem ter com os colegas.

Classe 2"Direito à educação", contabilizou $20 \%$ das U.C.E(s) e se refere à garantia da educação como condição necessária para uma vida digna.

Classe 3.A classe mais proeminente,entre as três obtidas, foi "Direitos no ambiente escolar", com $52 \%$ das respostas. Na análise da questão, essacategoria se referiuexclusivamente aos direitos que alunos possuem dentro da escola, como direito a um espaço físico que privilegie o aprendizado.

Merece atenção, a menor das classes fornecidas mediante a análise das respostas, com $20 \%$ das U.C.E(s), a classe 2, "Direito à educação". Mas a que educação os participantes estão se referindo? Seria sobre a educação e a sua universalidade e a não discriminação? Seria uma educação conservadora ou uma educação que vise emancipação, crescimento do indivíduo e inovação, flexibilidade e capacidade de adaptação a novos panoramas culturais e socioeconômicos?

Ressaltamos que nesta questão: "O que você entende por Direitos Humanos na escola?", o termo "Educação em Direitos Humanos" não aparece em qualquer das respostas, $28 \%$ dos discursos se encontram na categoria "Respeito dentro da escola", que pode tanto corresponder ao respeito ao ser humano, a uma cultura de paz, como também respeito à hierarquia. Algumas das respostas presentes nessa classe citam o respeito às diferenças, mas não há menção à distinção de classe social, característica étnico-racial, gênero, orientação sexual ou dificuldades escolares. 0 bullying aparece em algumas respostas como um acontecimento que cerceia a liberdade dos alunos.

Uma das principais características dos Direitos Humanos é a sua universalidade e a não discriminação. Há décadas os documentos da UNESCO (1960) apontam quatro características: disponibilidade, acessibilidade material, aceitabilidade econômica e adaptabilidade. A UNESCO entende por discriminação

(...) toda distinção, exclusão, limitação ou preferência fundada na cor, raça, no gênero, no idioma, na religião, nas convicções políticas ou de qualquer outra índole, na origem nacional ou social, na posição econômica ou no nascimento que tenha por finalidade destruir ou alterar a igualdade de tratamento na esfera do ensino, e em especial a) excluir uma pessoa ou um grupo do acesso aos diversos graus ou tipo de ensino, b) limitar um nível inferior a educação ou grupo de pessoas, c) instituir ou manter sistemas ou estabelecimento de ensino separados para pessoas ou grupos e d) colocar a pessoa ou um grupo em uma situação incompatível com a dignidade humana (UNESCO, Convenção relativa à Luta contra a Discriminação no campo do Ensino, 1960, Artigo 1).

Embora nos últimos 30 ou 40 anos o Brasil tenha dado saltos importantes procurando garantir uma educação para todos, ainda estamos longe de oferecer à nossa população o acesso e garantias legais, qualidade e universalidade, principalmente no sentido de criar condições necessárias para fazer da educação um forte instrumento de justiça social. O Ins- 
tituto de Pesquisa Econômica Aplicada (IPEA) possui um "Observatório da Equidade" (BRASIL, Observatório da Equidade, 2014)e, utiliza um conjunto de indicadores sobre raça, gênero, região geográfica, regularmente apresenta uma "radiografia" da educação e, os dados são sempre preocupantes, em todos os níveis de ensino.

Compreender "Direitos Humanos" na escola, diz respeito a considerar que as pessoas se diferenciam dos outros seres vivos por características inerentes à sua espécie: a capacidade de produzir conhecimento, de pensar suas práticas, como elemento fundamental da ação humana geral. Na nossa sociedade o conhecimento passa a ser uma das condições para a qualidade de vida e o alcance do bem estar social.

A respeito do pressuposto da educação conservadora ou emancipatória podemos nos reportar a Eyng (2013)que demonstra na pesquisa"Educação básica de qualidade para todos: políticas e práticas nos contextos das escolas públicas" $64 \%$ dos professores, $50 \%$ dos gestores e $80,15 \%$ dos pais de alunos possuem uma visão conservadora sobre qual seria a finalidade da educação escolar, isto é,para os participante, a educação se resume a um meio de garantir uma profissão aos alunos ou a transmissão de conhecimento técnico.

Por sua vez, a pesquisa "Projeto de Vida”, realizada pela Fundação Lemann (2015) feita com jovens egressos de escolas públicas, objetivou saber o que a escola significou para eles, mostra que os jovens se sentem mal preparados para lidar com os desafios da vida

7 Observatório da equidade: "A situação de baixa escolaridade do conjunto da população brasileira e as evidentes desigualdades no acesso e permanência na escola: a média nacional passou de 6,9 anos de estudo em 2005, para 7,9 anos em 2012, ainda abaixo dos 9 anos estabelecidos como ensino fundamental. As distâncias entre os grupos populacionais estão diminuindo, mas a desigualdade persiste: em 2012, a escolaridade média no Nordeste foi de 6,7 anos, enquanto no Sudeste foi de 8,5 anos; na zona rural foi de 5,1 anos, enquanto foi de 8,4 anos na área urbana; entre os pretos e pardos, foi de 7,1 anos, e entre os brancos, 8,7 anos; entre os $20 \%$ mais pobres, 5,3 anos; e entre os $20 \%$ mais ricos, 10,5 anos". Relatório de Observação $n .^{\circ} 5$, p 11. adulta e, um dos pontos de destaque foi um grande prejuízo em relação à comunicação.

Em relação ao saber experiencial, a escola não apenas transmite os conteúdos, mas também os vivencia, o que favorece que crianças e jovens, desde cedo, possam colocar em prática habilidades que levarão para suas vidas, assim como recursos estratégicos para exercer a cidadania.

Se, por um lado, o Brasil é signatário de inúmeros documentos referentes à Educação em Direitos Humanos, por outro, vemos a proliferação de um sistema de ensino fundamental e médio cuja finalidade é a preparação para os vestibulares. Tantas disciplinas que, em princípio, são discrepantes entre si, levam a um isolamento, o saber teórico acaba sendo visto como "sem sentido" para os jovens que vivem um momento de diversas crises, naturais de sua idade. Por sua vez lado, é lançado em 2018 o documento norteador para a Base Nacional Comum Curricular para a educação básica direcionado para o ensino por competências que traduzem a capacidade de alguém adquirir conhecimentos que serão expressos por meio de habilidades, atitudes e valores diante das "demandas complexas da vida cotidiana, do pleno exercício da cidadania e do mundo do trabaIho" (BRASIL, 2017, p.8). Um ponto que não deve ser esquecido é o movimento que efervesceu nas últimas duas décadas e que levou milhões de alunos às salas de aula nas universidades. Esse movimento se tornou uma grande fonte de investimentose negócios subsidiado por iniciativas governamentais. Porém, não houve uma alteração estrutural em relação à qualidade de muitas dessas instituições, que se configuram como "fábricas de diplomas". Essa mercantilização do saber, disfarçada de inclusão resultou na transformação das relações entre professores e alunosque não mais interagem na construção do conhecimento, pois foram convertidos em clientes.Como estão formados ou se formarão esses profissionais das licenciaturas, que deverão "ensinar por competências? Deixo essas conclusões para os leitores. 
Quando submetida ao Alceste, a questão 4 "O que você entende por Justiça na escola?",produziu três classes passíveis de análise:

A classe 1, denominada "Acesso e qualidade de ensino" (25\%), se refere à visão da justiça na escola por meio do acesso a níveis semelhantes de qualidade de ensino, bem como à criação de mecanismos para garantir a permanência dos alunos na escola, como demonstram as palavras que foram selecionadas pelo software: "educação”, "ensino”, "instituição" e "qualidade".

Na classe 2,"Igualdade de tratamento" (25\%), se percebe a justiça compreendida por meio do tratamento dispensado ao aluno, pelo professor, dentro da sala de aula.

A classe 3, "Direitos e deveres"(35\%) aponta a justiça como o respeito a direitos e deveres que membros da comunidade escolar conservam sejam eles alunos, professores ou funcionários da escola. Vale ressaltar que aspalavras"exercício da cidadania", "responsabilidade" "resolução de conflito", "dano moral", "respeito àdiversidade", "inclusão", "responsabilidade civil do professor e/ou da escola" não aparecem em qualquer dessas classes de respostas, dos participantes.

Algumas iniciativas emergem no país de forma esparsaem determinadas regiões. Podemos encontrar na internet, cartilhas elaboradas por ONGs ou por iniciativa de Programas das Universidades que são lançadas. Temos também a ideia de planos estratégicos de setores como o Conselho Nacional de Justiça (CNJ) com um programa denominado "Justiça na Escola" que em parceria com as Coordenadorias de Infância e Juventude dos tribunais de Justiça de todo país queraproximar o Judiciário e as instituições de ensino no combate e na prevenção dos problemas que afetam crianças e adolescentes, debater temas como combate às drogas, bullying, violência nas escolas, evasão escolar, sexualidade em todas as suas formas de expressão de gênero e identidade, prevenção de doenças sexualmente transmissíveis e cidadania, com a participação de juízes, professores, educa- dores, técnicos em psicologia e serviço social, alunos e pais e demais interessados. Mas todas essas iniciativas ainda não ressoam e não interferem significativamente na educação das infâncias e das juventudes para que realmente assimilem os "direitos e deveres" e a noção de justiça cidadã.

\section{A Abordagem dos direitos humanos NOS CURSOS}

Pra Não Dizer Que Não Falei de Flores Geraldo Vandré (1968)

Somos todos soldados, armados ou não Caminhando e cantando e seguindo a canção Somos todos iguais braços dados ou não Os amores na mente, as flores no chão

A certeza na frente, a história na mão Caminhando e cantando e seguindo a canção Aprendendo e ensinando uma nova lição

Vem, vamos embora, que esperar não é saber Quem sabe faz a hora, não espera acontecer

O instrumento de coleta de dados, além de demonstrar qual é a percepção da amostra quanto a direitos humanos e justiça, também visou detectar se a temática é de alguma forma abordada nos cursos que participaram da pesquisa.

Para tal finalidade, as três últimas questões, inicialmente objetivas (com as opções sim ou não), possibilitaram aos sujeitos também escrever e expressarcomo as temáticas concernentes à pesquisa eram abordadas em seu curso. Os dados foram analisados de forma quantitativa e qualitativa. 
Quanto aos cursos, todos os alunos do curso de Direito acreditavam que a temática era abordada ao longo do curso, 90\% dos alunos participantes do curso de Filosofia acreditavam que no seu curso a temática dos Direitos Humanos era de alguma forma abordada, assim como,os alunos dos cursos de Administração, História, Pedagogia e Psicologia(80\%). Os cursos relacionados à área de exatas demonstraram índices mais baixos; Ciências da Computação e Matemática, apenas 30\% dos participantes acreditaram que a temática era abordada.

Quanto à forma como o tema aparece nas disciplinas, os alunos do primeiro ano do Curso de Administração apontaram as disciplinas de Direito I e Recursos Humanos, já no quarto ano, registraram as disciplinas de Ética, Filosofia e Sociologia. No curso de Ciências da Computação, no primeiro ano, apenas um aluno indicou a disciplina "Antropologia Religiosa" como um espaço para discussão sobre Direitos Humanos e um dos alunos escreveu o seguinte: "Não diretamente com disciplinas para isso. E sim em conversas e diálogos, e como todos, devemos conhecer os nossos direitos, como humanos acima de tudo" (sic). Nenhuma disciplina foi mencionada pelos alunos do quarto ano.

No curso de Direito, os alunos do primeiro ano indicaram as disciplinas "Teoria Geral do Direito" e "Sociologia" como espaços nos quais o tema é discutido, apenas um aluno acredita que o tema aparece em todas as disciplinas. No quinto ano, a disciplina de "Direito Constitucional" foi a mais apontada, seguido pelos temas abordadosnas disciplinas de filosofia e sociologia.

Os alunos do primeiro ano de filosofia mencionaram que o tema é visto em disciplinas como Antropologia Cultural, Religiosa e Filosófica. Os alunos do último ano mencionaram alguns temas que foram abordados durante as aulas de Filosofia Moderna, Filosofia Política e palestras.

Os alunos ingressantes de História apontaram as disciplinas de Antropologia e Filosofia como disciplinas que fomentamdiscussões sobre como as leis foram constituídas e a influência destas na sociedade. Os concluintes do mesmo curso não indicaram qualquer disciplina específica, mas acreditavam que o tema transparecia junto à visão histórico-filosófica presente no curso.

No curso de Matemática, apenas um aluno ingressante acreditava que as aulas de Antropologia eram um espaço de discussão sobre Direitos Humanos. Os concluintes apontaram "Psicologia da Educação". No curso de Pedagogia, os alunos do primeiro ano citaram os debates, os vídeos e as conversas em sala de aula como espaços propícios para a discussão a respeito do tema. Os do terceiro ano apontaram a LDBEN (BRASIL,1996), os estágios e as aulas sobre políticas públicas.

No curso de Psicologia, os alunos ingressantes não apontaram uma disciplina específica, mas fizeram comentários sobre o curso tratar especialmente sobre a compreensão do ser humano. Os participantes do quinto ano indicaram as disciplinas "Políticas Públicas", "Psicologia Jurídica" e "Ética profissional", além de acreditarem que os estudos de caso favorecem a reflexão sobre Direitos Humanos, porém, um dos alunos mencionou que faltava um enfoque específico do curso acerca do tema. Os alunos de licenciatura em Psicologia não relacionaram o assunto Direitos Humano a uma única disciplina, mas apontaram os debates que envolvem ética, além da proposta de o curso favorecer o reconhecimento do "respeito ao próximo".

Para muitos alunos, de diferentes cursos, a disciplina "Antropologia" é um dos espaços para a discussão sobre Direitos Humanos. A disciplina em questão faz parte da configuração curricular de todos os cursos e está alinhada ao caráter confessional da instituição onde a pesquisa foi realizada.

Ainda assim, para cursos como Licenciatura em Matemática, onde os egressos estarão em contato com jovens e crianças, seria necessário um maior embasamento quanto às questões relativas à Educação em Direitos Humanos. 
Esses dados mostram que o princípio de educar para os Direitos Humanos envolve o desenvolvimento da consciência desde a educação básica até o ensino superior enquanto possibilidade de promover a boa convivência, o respeito pelo outro epor conseguinte, até enfraquecer os ciclos de violências. Segundo Estevão:

A educação constitui-se como um dos lugares naturais de aplicação, consolidação e expansão dos direitos humanos; como um direito-chave cuja negação é especialmente perigosa para o princípio democrático da igualdade civil e política; como uma arena de direitos e com direitos; enfim, como um outro nome da justiça. (ESTEVÃO, 2011, p.14).

Quanto à questão "No seu curso são tratadas questões relativas a justiça?”, $64,70 \%$ da amostra respondeu positivamente, a questão, dentro desse percentual, $15,2 \%$ da amostra acredita que a temática é abordada dentro de uma disciplina específica. Quanto aos cursosCiências da Computação e Matemática apresentaram os índices mais baixos. Os participantes do curso de Matemática responderam em unanimidade "Não".Por sua vez, os participantes do curso de Direito responderamunanimemente "Sim".

Mesmo que os alunos tenham assinalado que em seus cursos a temática é abordada, muitos não discorreram sobre como isso é feito.Apresentaram apenas uma ou outra disciplina, portanto, parece que não percebem a necessidade de uma abordagem transversal e contextualizadapor meio de questionamentos e reflexões a respeito das práticas, da teoria, do saber e da ideologia. Nesse sentido, reiteramos que o currículo exerce um importante papel e, muitas vezes decisivo no processo de afirmação dos sujeitos e de suas identidades. Como ressalta Candau (2010, p. 404), "[...] a cultura escolar se encontra, muitas vezes, tão 'engessada', pensada de uma maneira tão rígida e monolítica, que, dificilmente, deixa espaço para que a cultura dos Direitos Humanos possa penetrá-la [...]".

Segundo uma pesquisa de opinião realizada pela Secretaria de Direitos Humanos da Presidência da Repúblicaa respeitodas percepções da população sobre direitos humanos, cujos dados foram analisadospor Venturi (BRASIL, 2010a), pode-se constatar que uma grande parcela da população brasileira"tende a reconhecer o caráter universalista dos direitos humanos e sua relevância para o bem comum; a reivindicá-los, mesmo quando não o reconheçam como tais; e a apoiar as políticas voltadas para sua promoção (...) ( BRASIL, 2010 a, p.17), embora essa parcelanão conheça devidamente o significado de "DireitosHumanos".

Devemos considerar os esforços da UNESCO no Brasil para fornecer elementos para a formulação de políticas pública, no entanto continuamos sem projetos e políticas públicas efetivas na prevenção adiferentes formas de violências como bullyinghomofóbico, discriminação da mulher, aprendizagem de convívio, sentimento de pertencimento, respeito à preservação da vida, honestidade, cidadania,corrupção, respeito à pluralidade, nacionalidade, cor, gênero, classe social, cultura, crença religiosa, orientação sexual e opção política, ou qualquer diferença. Não seriam essas questões justamente as que englobam os Direitos Humanos e Justiça?Eainda não estão ecoando na percepção e no comportamento dos alunos?

Na prática dos Direitos Humanos,e da justiça, está explícito o imenso aparato de saberes que, de diversas formas, vão interferir nos modos de existência, assim, precisamos trabalhar para essa prática acontecer no universo da escola.Isso pressupõe uma mudança dos currículos, dos planos de ensino e, por consguinte das práticas curriculares.

O currículo deve vislumbrar a formação de sujeitos de direito capazes de conhecer, reivindicar e lutar por seus direitos de modo a 
romper com a cultura de silêncio e impunidade que ainda se mostra fortemente presente (SILVA, 2015, p. 477).

Nas sociedades contemporâneas, a população jovemé cada vez mais confrontada com processos de exclusão social, com diferenças religiosas, étnicas e racionais, e com as desvantagens e vantagens da globalização. A Educação para os Direitos Humanos aborda essas questões e pode ajudar a criar sentido das diferentes crenças, atitudes e valores, e das aparentes contradições das sociedades multiculturais modernas nas quais os jovens vivem.

É preciso incorporar ao processo educativo que Direito é exercício e é prática humana de política. A educação, enquanto direito que promove outros direitos, deve converter-se numa cultura política dos Direitos Humanos. Tal entendimento implica aurgência da universidade rever e promover de forma obstinadaa educação em Direitos Humanos, com capacitação eformação de professores, coordenadores, funcionários de apoio e a partir dessa ação desencadear ações para a formação do aluno, o que irá contribuir para a propagação do compromisso social e para uma cultura de paz.

Pra Não Dizer Que Não
Falei de Flores
Geraldo Vandré (1968)
Caminhando e cantando
e seguindo a canção
Somos todos iguais,
braços dados ou não
Nas escolas, nas ruas,
campos, construções
Caminhando e cantando
e seguindo a canção
Aprendendo e ensinando
uma nova lição

\section{REFERÊNCIAS}

ALCESTE. Versionwindow:um longivel d'analyse de donnéstextuelles: Manuel d'utilisation, Image, $2010.46 \mathrm{p}$.

BARDIN, L. Análise de conteúdo.3ed. Lisboa: Edições 70, 2000,229 p.

BOBBIO, N. A era dos direitos.4 ed. Rio de Janeiro: Campus, 1992,97 p.

BRASIL. Base Nacional Comum Curricular (BNCC). Ministério do Estado da Educação. Secretaria executiva e Secretaria de Educação Básica, 2017. Disponível em: http://portal.mec.gov.br/index. php?option=com_docman\&view=download\&alias=78231-anexo-texto-bncc-reexportado-pdf-1\&category_slug=dezembro-2017-pdf\&Itemid=30192. Acesso em: 10 jun. 2018.

BRASIL. Observatório da equidade. As desigualdades na escolarização no Brasil: relatório de observação n 5 . Brasília: Presidência da República, Conselho de Desenvolvimento Econômico e Social - CDES, 2014.60 p. Disponível: http//www.cdes.gov.br. Acesso em:11 jun. 2018.

BRASIL. CNJ. Conselho Nacional de Justiça. Cartilha 2010. Projeto Justiça nas escolas. Disponível em: http://www.cnj.jus.br/images/programas/justica-escolas/cartilha_bullying.pdf. Acesso em: 11 jun. 2018.

BRASIL. Presidência da República. Direitos humanos: percepções da opinião pública: análises de pesquisa nacional / organização Gustavo Venturi. - Brasília: Secretaria de Direitos Humanos, 2010a, 272 p.

BRASIL. Resolução CNE/CEB 4 de 13 de julho de 2010. Define Diretrizes Curriculares Nacionais Gerais para a Educação Básica.Diário Oficial da União, Brasília, DF, 14 jul. 2010b, Seção 1. 
BRASIL. Decreto No 6.094 de 24 de abril de 2007a.Plano de Metas: Compromisso Todos pela Educação. Brasília, DF.

BRASIL. Comitê Nacional de Educação em Direitos Humanos. Plano Nacional de Educação em Direitos Humanos (PNEDH) / Comitê Nacional de Educação em Direitos Humanos. - Brasília: Secretaria Especial dos Direitos Humanos, Ministério da Educação, Ministério da Justiça, UNESCO, 2007b.

BRASIL. Lei nº 9.394, de 20 de dezembro de 1996. Estabelece as diretrizes e bases da educação nacional. Diário Oficial [da República Federativa do Brasil], Brasília, DF, v. 134, n. 248, 23 dez. 1996.Seção I, p. 27834-27841.

BRASIL. Lei 8.069de 13 de julho de 1990. Legislação correlata. Estatuto da Criança e do Adolescente.12. ed.Brasília, DF, 2014. Série Legislação.

BRASIL. Constituição da República Federativa do Brasil de 1988.Disponível em: http://www. planalto.gov.br/ccivil_03/Constituicao/Constituiçao.htm. Acesso em: 6 mai. 2017.

CALIMAN G.(Org.) Juventude universitária: percepções sobre justiça e direitos humanos,1. ${ }^{a}$ ed. Brasília: Liber Livro, 2016.253 p.

2013, 200 p.

Violências e direitos humanos: espaços da educação,1. ${ }^{a}$ ed. Brasília: Liber Livro,

CANDAU, V.(Org.).Sociedade, Educação e Cultura(s):questões e propostas,3. ed. Petrópolis: Vozes, 2010, $211 \mathrm{p}$.

DELORS, J. et al. Educação: um tesouro a descobrir. 2 ed. São Paulo: Cortez, 1998. 240 p.

DEL PRETTE, Z. A. P.; DEL PRETTE, A. Psicologia das relações interpessoais: Vivências para o trabalho em grupo,1. ${ }^{\circ}$ ed. Petrópolis, RJ: Vozes, 2001,232 p.

ESTEVÃO, C.V.Democracia, Direitos Humanos e Educação: Para uma perspectiva crítica de educação para os direitos humanos. Revista Lusófona de Educação. Lisboa,n. 17, 2011. Disponível em:

http://www.scielo.gpeari.mctes.pt/scielo.php?script=sci_arttext\&pid=S1645-72502011000100002\&lng=pt\&nrm=iso. Acesso em: 7 mai. 2017.

ESTEVÃO, C. V. Educação, conflito e convivência democrática.Ensaio: Avaliação e Políticas Públicas em Educação. Rio de Janeiro, v. 16, n. 61, p. 503-513, 2008. Disponível em: http://www. scielo.br/scielo.php?script=sci_arttext\&pid=S010440362008000400002\&lng=en\&nrm=iso. Acesso em: 17 jan. 2017.

EYNG, A M. Educação em Direitos humanos no currículo escolar: o projeto político pedagógico como espaço de garantia ou violação de direitos. In: . (Org.). Direitos humanos e violências nas escolas: desafios e questões em diálogo, $1^{\circ}$ ed. Curitiba, PR: CRV, 2013, cap. 3, p. 29-58, 259 p.

FUNDAÇÃO LEMANN. Projeto de Vida: O papel da escola na vida de jovens. São Paulo, 2015. Disponível em:http://www.fundacaolemann.org.br/wp-content/uploads/2015/06/pesquisa_projeto_de_vida_apresentacaopdf. Acesso em: 27 mar. 2018.

KOEHLER, S.M. F.; SANTOS, D. T. Convivência escolar: representações de alunos de ensino superior. Anais do XII EDUCERE. Congresso de Educação da PUC/PR, 26 a 29 de outubro de 2015. 
LIMA. L. C.Programa Alceste, primeira lição: a perspectiva pragmatista e o método estatístico. Revista de educação pública, v. 17, n.33, p. 83-97, jan./abr. 2008. Disponível em:http://132.248.9.34/ hevila/Revistadeeducacaopublica/2008/no33/6.pdf. Acesso em: 14 out. 2017.

MOLINARI, A. M. C. A construção da moralidade e a formação de sujeitos éticos: contribuição da Psicologia Genética para educação escolar. In:

GOMES, C. A.; FERREIRA, G. A. KOEHLER, S. M. F. (Orgs.), $1^{\circ}$ ed. Culturas de violência, culturas de paz: da reflexão à ação de educadores, operadores de direito e defensores dos direitos humanos. Curitiba,PR: CRV, 2012, 341 p.

ONU. Declaração Universal dos Direitos Humanos. Adotada e proclamada pela resolução $217 \mathrm{~A}$ (III) da Assembléia Geral das Nações Unidas em 10 de dezembro de 1948. Disponível em: http:// portal.mj.gov.br/sedh/ct/legis_intern/ddh_bib_inter_universal.htm. Acesso em: 10 dez. 2017.

PIAGET, J.O juízo moral na criança. 3. ed. São Paulo: Summus, 1994, 304 p.

SILVA, A. T. R. Educação em Direitos Humanos: o currículo entre o relativismo e o universalismo. Educ. Soc., Campinas, v. 36, nº. 131, p. 461-478, abr./jun. 2015.

UNESCO. Plano de Ação do Programa Mundial para Educação em Direitos Humanos. Nova York/ Genebra: UNESCO/ONU. 2006. 58 p.

UNESCO. Convenção relativa à Luta contra a Discriminação no campo do Ensino.Adotada a 14 de dezembro de 1960, pela Conferência Geral da UNESCO, em sua $11^{\text {a }}$ sessão, reunida em Paris de 14 de novembro à 15 de dezembro de 1960. Disponível em: http://unesdoc.unesco.org/ images/0013/001325/132598por.pdf. Acesso em: 12 jun. 2018.

VANDRÉ, G. Para não dizer que não falei das flores. (Caminhando). Duração 6.49.Álbum Som Livre, 1968.

Submetido em: 16-8-2018

Aceito em: 20-12-2018 